\title{
Apresentação: Narrativas fora do lugar
}

Leila Lehnen $^{1}$

Assim como o mapa material, o mapa simbólico de uma nação, composto por diferentes tipos de narrativas escritas e orais, tem seus territórios centrais e suas zonas periféricas, espaços marginais, que contêm discursos ex-cêntricos, narrativas que sobrevivem "fora do lugar", aquém ou além dos discursos nacionais hegemônicos. Estas zonas periféricas existem em um constante, ainda que por vezes tenso, diálogo com os territórios centrais da cartografia simbólica de uma nação - o que também pode gerar uma espécie de fluidez entre os dois espaços. Desta forma, certas narrativas ex-cêntricas podem ser apropriadas pelo discurso hegemônico (Williams, 1977). Em seu lugar surgem outras, que não somente articulam os mecanismos de exclusão inerentes a qualquer configuração sociopolítica e cultural mas também lutam por criar um espaço de expressividade para os sujeitos que vivem às margens da sociedade hegemônica e de seus mecanismos de validação política, social e cultural.

Embora possa ser fácil identificar quais são os territórios simbólicos centrais e quais são os espaços periféricos dentro da cartografia imaginária de uma nação, as fronteiras costumam ser mais obscuras. Se em geral as narrativas de minorias étnicas, de setores sociais espoliados, de mulheres e de sujeitos não heterossexuais localizam-se nos espaços marginais/marginalizados do mapa simbólico nacional, também os discursos de outros grupos, como imigrantes ou minorias religiosas, podem ser relegados aos espaços simbólicos ex-cêntricos. Estas exclusões, muitas vezes, são óbvias e violentas; outras vezes, se dão por meios mais sutis, como a partir do obscurecimento da diferença destes setores, que acabam por ser assimilados dentro da narrativa nacional hegemônica sem que se leve em conta suas particularidades socioculturais ou outros tipos de distinções.

Outros discursos que se localizam na fronteira entre centro e periferia simbólica são as narrativas que desafiam as classificações de gênero artístico, textos ou produções culturais que cruzam os limiares

\footnotetext{
${ }^{1}$ Doutora em literatura espanhola e brasileira e professora de literatura brasileira da University of New Mexico, Albuquerque, Estados Unidos. E-mail: llehnen@unm.edu
} 
entre imagem, som e (diferentes tipos de) palavra escrita. Ao traçar uma cartografia imaginária fluida da nação e do próprio artefato cultural, este tipo de narrativa questiona a dicotomia entre centro e periferia e interroga o conceito de uma narrativa nacional unidimensional. E, ao postular esta interrogação, tanto textos ex-cêntricos quanto textos "fronteiriços" também desestabilizam as narrativas simbólicas hegemônicas, abrindo espaços para a inclusão das margens, da periferia não somente simbólica mas também geossocial. A liminalidade se confunde com a centralidade, criando um espaço simbólico novo, uma zona de intersecções.

Em seu livro O local da cultura (1998), o teórico pós-colonial Homi K. Bhabha questiona a ideia de uma narrativa nacional homogênea. Em vez de uma articulação homogênea, "holística", da nação, Bhabha propõe que as narrativas nacionais não somente no âmbito pós-colonial, mas também em geral, tomem em conta a hibridez dos discursos que fazem parte destas narrativas. Assim, Bhabha argumenta que

é no surgimento dos entre-lugares - a sobreposição e o deslocamento de esferas da diferença - que as experiências intersubjetivas e coletivas de nacionalidade, interesse comunitário, e valor cultural são negociados. [...] A representação da diferença não deve ser lida de forma apressada como o reflexo de um conjunto de características étnicas ou culturais preestabelecidas dentro de uma tradição. A articulação social da diferença, desde uma perspectiva minoritária, é uma negociação complexa e contínua que tenta autorizar hibridezes culturais que surgem no momento de transformações históricas (Bhabha, 1998, p. 2).

Para Bhabha, os entre-lugares da cultura permitem a emergência de uma diferença que não necessariamente implica alteridade, mas, sim, uma diferença que resulta de e que possibilita formas de ser, de pensar e de se expressar híbridas. Esta hibridez - que pode conter diferentes combinações culturais, sociais, étnicas, políticas - por sua vez pode desafiar a constituição e a dominação de uma narrativa nacional hegemônica, centrada em oposições como centro e periferia, dominante e subalterno, nacional e estrangeiro.

Ao se centrar no eixo espaço e memória - dois elementos de importância fundamental na constituição de uma narrativa nacional (assim como de suas exclusões explícitas e implícitas) -, este dossiê procura justamente esta hibridez, o entre-lugar de narrativas simbólicas 
que permita uma contestação de um imaginário nacional (no seu sentido não apenas cultural mas também social e político) hegemônico.

Os textos incluídos aqui evidenciam, de certo modo, um ímpeto se não contrário, pelo menos contestador ao descrito por Benedict Anderson em Comunidades imaginadas: reflexões sobre a origem e a expansão do nacionalismo (2005). Anderson argumenta que no século XIX a palavra impressa - jornais, livros, folhetins - ajudou na consolidação de uma comunidade nacional imaginada. Através da circulação de informação, pessoas de diferentes regiões, de diferentes etnias e, até certo ponto, de diferentes estratos sociais se imaginavam como parte de um todo nacional. A formação de uma comunidade imaginada supõe uma homogeneização dos seus componentes. A diferença fica do lado de fora. Fora também estão as outras comunidades nacionais. Em outras palavras, a coesão cria diferenciação, mas uma diferenciação que implica o apagamento da alteridade. Já os textos deste dossiê revelam o lado obscuro, as vozes muitas vezes silenciadas da comunidade imaginada. Traçam, assim, uma cartografia alternativa da nação.

Este mapeamento se centra nos espaços geoimaginários liminais. No entanto, a liminalidade é implícita ou explicitamente contraposta e/ou justaposta aos territórios simbólicos centrais, às narrativas hegemônicas. Em outras palavras, os textos críticos incluídos neste dossiê sugerem um diálogo entre centro e margens. Lidam com "narrativas fora do lugar", textos até certo ponto ex-cêntricos ou que abordam questões de marginalidade em suas diferentes manifestações (social, racial, étnica, de gênero, geográfica). Esta ex-centridade se configura a partir de dois nódulos: a memória, tanto a histórica quanto a pessoal, e o espaço, tanto físico quanto simbólico.

A ideia do entre-lugar e da margem aparece em vários dos trabalhos que lidam com o eixo organizador do espaço. No artigo de Paulo C. Thomaz, "Des-reterritorialização: percursos possíveis do romance afro-brasileiro recente", a ex-centricidade se dá pelo viés do deslocamento territorial, discutido a partir do romance Um defeito de cor, de Ana Maria Gonçalves. Centrando-se no conceito da "multiterritorialidade", elaborado pelo geógrafo Rogério Haesbaert, Thomaz interpreta os vários percursos territoriais da protagonista do romance, Kehinde. Seus movimentos entre diferentes continentes (África-Brasil) e dentro da geografia nacional (Brasil) implicam, segundo o autor, não uma "desterritorialização desenraizadora", mas 
algo mais complexo, uma contínua reterritorialização. Este processo, por sua vez, tem conotações nas esferas simbólica e cultural, bem como nos âmbitos político e econômico. Thomaz nos sugere, assim, a imagem de uma cartografia móvel, de um continuado negociar de fronteiras materiais e simbólicas que desafiam a polaridade entre exclusão e inclusão.

A ideia de deslocamento físico e simbólico, de passagens, também está presente no texto de Vinícius Mariano de Carvalho, “Escrevendo-se na cidade: Exu como o Guia afetivo da periferia, de Marcus Vinicius Faustini". O autor propõe a escrita como uma performatização da cidade, que reorganiza os paradigmas que estruturam a percepção do espaço. Carvalho lê o livro de Faustini a partir da figura de Exu, orixá mensageiro que simboliza movimento, passagem, transformação, comunicação. Ao usar este orixá como instrumento hermenêutico, o artigo se distancia de uma perspectiva etnocêntrica ou "subalternizante" da produção literária brasileira (assim como Faustini desconstrói a divisão urbana). Carvalho enfatiza, então, a liberdade, inclusive a de circulação, de criar diferentes identidades e de estabelecer novas ferramentas interpretativas.

Em "Espaços ficcionalizados em Desterro: memórias em ruínas, de Luís S. Krausz: um ensaio em geografia literária", Georg Wink também aborda a intersecção entre literatura e geografia, analisando o romance de Luís S. Krausz a partir da ótica do que denomina de "geografia literária". Segundo Wink, a geografia literária tem como objetivo não somente revelar os nexos entre textos literários e espaços (tanto reais como imaginários) mas também criar uma cartografia literária que dialogue com o processo hermenêutico do texto literário.

Sophia Beal, em "A arte de andar nas ruas de Brasília", também se concentra nas relações entre espaço físico e espaço simbólico, território cultural e território urbano. $\mathrm{O}$ artigo revela como as ruas de Brasília são representadas na produção artística e como essa produção influencia na própria percepção do território urbano. Usando como aporte teórico as ideias de Michel de Certeau sobre a invenção do cotidiano, Beal se debruça sobre o modo como a arte recria o espaço da urbe, desestabilizando hierarquias, retraçando mapas reais e imaginários, questionando exclusões e reposicionando significados. Ela analisa os poemas de Nicolas Behr e os textos de escritores como José Rezende Jr. e Liziane Guazina discutindo como eles re-imaginam e, assim, re- 
configuram os espaços da capital brasileira, muitas vezes em diálogo com outros artefatos culturais, como as canções da banda Legião Urbana.

A intersecção entre espaço e poesia é também o foco de Susanna Busato, no artigo "O espaço urbano como construção poética do sujeito". Abordando a representação da cidade em Fábio Weintraub, ela propõe que seus poemas constroem o espaço como uma criação do sujeito poético e de sua memória sensível. Trata-se, nas palavras da autora, de uma "espacialização do instante", que capta e privilegia a perspectiva do objeto do olhar. Este olhar poético sobre a cidade revela uma imagem não idealizada da metrópole contemporânea, focando-se nos seus espaços e sujeitos limiares, ex-cêntricos.

A poética do espaço e a poesia da linguagem são os temas desenvolvidos no texto de Rosane Carneiro Ramos, "O não espaço em Wesley Peres: narrativas líricas em deslocamento", que discute os limites entre prosa e poesia no romance Casa entre vértebras. A partir do conceito do não espaço a autora demonstra como a narrativa lírica desestabiliza a ideia de lugar (Certeau) ao desafiar a sua suposta fixidez. A linguagem poética aponta para um questionamento existencial e uma transformação, além de uma possível superação da realidade, incluindo a realidade espacial. Finalmente, o artigo traça uma possível genealogia de autores nacionais cujas obras evidenciam forte carga subjetiva e que deveriam ser analisadas desde a perspectiva do entrelaçamento entre poesia e prosa.

O espaço - seja ele concreto, como as ruas de Brasília ou de São Paulo, ou metafórico, como os mapas literários propostos por Wink ou a casa que aparece no romance de Wesley Peres - é sem dúvida um fator decisivo na formação de narrativas hegemônicas. A espacialidade em geral implica um centro e uma periferia, um dentro e um fora. O espaço é, assim, fundamental na formação de territórios nacionais e também joga um papel importante nas narrativas nacionais - basta pensar no projeto "geográfico" de José de Alencar, a sua tentativa de representar as diferentes regiões brasileiras como parte de uma narrativa da nação. Mas, como sugere a obra do próprio Alencar, a memória, seja histórica ou individual, é um fator complementar na geração de narrativas totalizantes e excludentes. Neste contexto, o retrabalhar, o desestabilizar da(s) memória(s) pode gerar novos territórios de inclusão cultural e social.

A memória coletiva, apropriada e transformada pelos setores sociopolíticos dominantes, forma um dos pilares da narrativa nacional hegemônica. Esta história "oficial" pode ser usada como instrumento de 
dominação, criando e justificando exclusões e até mesmo formas de violência oficial. Os textos que lidam com a temática memorialística e/ou histórica neste dossiê abordam uma visão histórica que - embora dialogue com a narrativa "oficial" - também diverge desta narrativa, oferecendo uma visão crítica da história nacional e da memória em geral. Neste contexto a memória pode se transformar em um espaço de resistência.

Esta proposta é desenvolvida por Cristina Ferreira-Pinto Bailey em "Sincronicidades: história, memória e ficção em Ana Maria Machado e Griselda Gambaro". No seu artigo, Bailey mostra como a perspectiva centrada em micro-histórias de sujeitos ex-cêntricos em romances históricos da escritora brasileira Ana Maria Machado e da autora argentina Griselda Gambaro questiona o conceito da nação como uma unidade simbólica. A fragmentação da ideia de nação, assim como de identidade nacional, se dá não somente pela abordagem dos romances de Machado e Gambaro, mas pela própria perspectiva comparativa que borra as fronteiras das chamadas "literaturas nacionais".

A memória coletiva e a lembrança pessoal são dois fatores importantes na articulação de identidades de sujeitos migrantes. Na experiência destes sujeitos, a memória está frequentemente atrelada à ideia do espaço e do tempo - o país de origem/ o passado vs. (ou complementando) o país de destino/ o presente e possivelmente o futuro. Estes três vetores: memória, espaço, temporalidade são os eixos que organizam os artigos de Cecily Raynor.

Júlia Braga Neves, em "Um sentido para o fim: espaços migratórios e melancolia em Hanói, de Adriana Lisboa", lida com duas temáticas paralelas e interconectadas. A primeira parte do artigo estabelece uma comparação entre o espaço material da cidade (no caso, Chicago) e o espaço mental das memórias dos protagonistas do romance de Lisboa. O espaço material serve como uma espécie de cartografia do espaço mental. E a relação entre ambos influencia a composição estética do romance, que oscila entre crônica e romance psicológico. A relação entre o espaço físico e o espaço simbólico também aponta para a constante desterritorialização experimentada pelo sujeito migrante. A segunda parte do ensaio analisa a constituição das identidades migratórias, de sujeitos que vivenciam a desterritorialização de diferentes formas. Constituídas a partir das memórias e histórias dos personagens (i)migrantes, estas são identidades melancólicas. Segundo Braga Neves, 
a melancolia dos personagens de Hanói, por sua vez, implica uma falta de agência, uma passividade em relação à cultura racista que os rodeia.

A interface entre memória e espaço e como estes dois marcam a identidade dos sujeitos migrantes é também o foco de Cecily Raynor, em "Linguagem, espaço e nação: um mapeamento das identidades multigeográficas do protagonista imigrante". A autora discute a intersecção entre o espaço e a migração nos romances Mar paraguayo, de Wilson Bueno, e Estive em Lisboa e lembrei de você, de Luiz Ruffato. $\mathrm{O}$ artigo revela como a representação do sujeito migrante e da experiência da migração nestes dois romances desestabiliza a "coesão narrativa tempo-espaço", levando a um questionamento das categorias "nacional" e "transnacional". As narrativas de Bueno e Ruffato formulam, assim, novas categorias espaciais (mnemônicas, transnacionais e linguísticas) que, por sua vez, afetam discursos de identidade, ancorados em territórios da memória.

O dossiê conclui com uma cartografia de natureza mais íntima. O artigo de Gabriel Estides Delgado, "A classe feita corpo: pertencimento e discriminação social em Inferno provisório, de Luiz Ruffato", traça um mapa da materialidade (e da ideologia materialista) em dois romances do escritor mineiro. Delgado revela a ideologia materialista que permeia os dois últimos volumes de Inferno provisório, O livro das impossibilidades e Domingos sem deus, apontando como esta ideologia se faz presente, por um lado, na descrição física dos personagens - a aparência, composta da corporalidade e do vestuário dos personagens, funciona como indicador das relações de classe. Tratase de um "olhar social que reifica os corpos". Por outro lado, a lógica materialista também transparece na incorporação de objetos dentro das narrativas de Ruffato. Tanto a representação física quanto a enumeração de objetos nos textos discutidos apontam para os mecanismos da violência social que permeiam a sociedade brasileira. Neste artigo o mapeamento social e cultural das margens se dá a partir das coordenadas particulares, dos corpos individuais, dos objetos de consumo que estes corpos desejam, adquirem ou não adquirem.

Os textos incluídos neste dossiê nos revelam como a literatura pode servir como forma de resistência contra parâmetros culturais fixos e, portanto, potencialmente excludentes. Ao cruzar fronteiras entre literaturas nacionais e confins linguísticos e de gênero, entre centros e periferia, espaços mnemónicos e outros tipos de territórios físicos e 
simbólicos, os textos desta coletânea estabelecem potenciais espaços de expressão híbridos, entre-lugares culturais.

\section{Referências}

ANDERSON, Benedict (2005). Comunidades imaginadas: reflexões sobre a origem e a expansão do nacionalismo. Lisboa: 70.

BHABHA, Homi K. (1998). O local da cultura. Tradução de Myriam Ávila, Eliana L. L. Reis e Gláucia R. E. Gonçalves. Belo Horizonte: Ed. UFMG.

WILLIAMS, Raymond (1979). Marxismo e literatura. Tradução de Waltensir Dutra. Rio de Janeiro: Zahar. 